\section{Adolescent psychiatric in-patients}

\author{
A high-risk group for premature death \\ ELLEN KJELSBERG
}

\section{Background Research has \\ demonstrated increased mortality rates in \\ adolescent psychiatric in-patients.}

\begin{abstract}
Aims To investigate this excess mortality by calculating standardised mortality ratios (SMRs) relative to cause of death, diagnosis, cohort and age.

Method A nationwide Norwegian sample of 1095 former adolescent psychiatric in-patients were followed up 15-33 years after first hospitalisation by record linkage to the National Death Cause Registry.
\end{abstract}

Results The SMR was significantly increased for almost all causes of death investigated. In males, all psychiatric diagnoses had significantly increased SMRs, whereas in females, organic mental disorder, anxiety disorder and affective disorder had non-significantly increased SMRs. The SMR was significantly elevated for all age-spans and cohorts investigated.

\section{Conclusions Abroad prevention} strategy is needed to combat the increased mortality rates found in adolescent psychiatric in-patients.

Declaration of interest Funded by a grant from the Foundation for Health and Rehabilitation through the Norwegian Council for Mental Health.
Harris \& Barraclough (1998) have recently completed an extensive review of research into mortality in mental disorders. Among 152 reports fulfilling strict guidelines for acceptance, a total of six papers reporting mortality in child and adolescent psychiatric patients were included in the metaanalysis (Goldacre \& Hawton, 1985; Kuperman et al, 1988; Rydelius, 1988; de Chateau, 1990; Larsen et al, 1990; Östman, 1991). These studies were based on a total population of 7536 patients, mostly Scandinavian. Combining the results from these six studies, Harris \& Barraclough found that the all-causes mortality risk was 2.8 times the expected in child and adolescent psychiatric patients. We reported earlier (Kjelsberg \& Dahl, 1998) on the mortality rates in a nationwide Norwegian sample of 1095 adolescent psychiatric in-patients. We wanted to investigate the excess mortality further by calculating standardised mortality ratios (SMRs) relative to cause of death, diagnosis, cohort and age. This has not, to our knowledge, been done before.

\section{METHOD}

\section{Population}

The study population has been described elsewhere (Kjelsberg \& Dahl, 1998). It consisted of all patients consecutively admitted to the adolescent unit at the National Centre for Child and Adolescent Psychiatry in Oslo, Norway, during the years 19631981. The hospital was the only in-patient facility for adolescent psychiatric patients in the country at the time, and no regional admission rules were in force; thus, the sample can be considered nationwide. Altogether, $93.4 \%$ of all patients were traced successfully in official registers. Of these, 53 had emigrated and had to be excluded, together with 42 patients for whom the medical records were missing or incomplete. Thus, a total of 1095 patients $(85.8 \%$ of the original sample) entered the comprehensive mortality study undertaken by us.

For these 588 males and 507 females, mean age was 15.0 years at admission (s.d. $=1.6$, range $=11-22$ ) and 39.5 years at follow-up (s.d. $=5.5$, range $=28-51$ ). The mean follow-up period from first admission was 24.5 years (s.d. $=5.5$, range $=15-33$ ). The population was followed for a total of 25268 person-years.

Based on the hospital records, all patients were rediagnosed according to the diagnostic criteria in DSM-IV (American Psychiatric Association, 1994). An interrater reliability study yielded satisfactory results, with kappa $=0.79$. The largest diagnostic group was disruptive behaviour disorder (DBD), which comprised 55.3\% of the patients. A total of $13.9 \%$ had a personality disorder, and a psychotic disorder was found in $8.9 \%$ of the patients. The rest of the population consisted of about equal groups with mood disorder, anxiety disorder, psychoactive substance use disorder (PSUD) and organic mental disorder, with the remainder suffering other mental disorders. Comorbidity was frequently encountered, with $51 \%$ of the patients having more than one disorder. The disorder dominating the clinical picture was considered to be the main diagnosis. Psychoactive substance use disorder was the comorbid disorder most often reported, with $36.5 \%$ of those with DBD having a concurrent PSUD. Patients with DBD were dichotomised according to concurrent PSUD or not.

\section{Statistical methods}

The observed number of deaths in the study population and the causes of these deaths were determined by linkage of the patient list to the National Death Cause Registry. The register is based on personal identification numbers and includes all death certificates for the Norwegian population. The cause of death had been established in all cases and was recorded according to the ICD-9 classification (World Health Organization, 1977).

For each patient, the gender, birth year and first admission year were recorded, together with diagnosis at hospitalisation and, when applicable, year and cause of death. Hospital admissions and deaths were averaged to have occurred in the middle of the calendar year. Thus, the admission year and the death year counted as half a year, and each interposed year counted as 
one year. For people who did not die, full person-years were registered up to and including 1995, the last year of the observation. Person-years in the study were arranged according to birth year in cohorts.

To calculate the expected mortality in the corresponding cohorts in the general Norwegian population, mortality data pertaining to the total Norwegian population were employed for all cohorts of interest, with calculations performed for each gender separately. The mortality tables arrived at in this manner could then be used to calculate the expected numbers of deaths by cause of death, mental disorder, cohort and age for each gender.

The SMR is the observed number of deaths divided by the expected number of deaths, multiplied by 100 . To test the statistical significance of the SMR we assumed that the observed number of deaths followed a Poisson distribution. Confidence intervals for SMR were computed using the CIA computer program (Gardner \& Altman, 1989a). A 95\% confidence interval (95\% CI) was chosen. The SMR is significantly elevated if the lower confidence interval is $>100$ and significantly reduced when the upper confidence interval is $<100$.

We wanted to compare the SMRs found for different cohorts in a meaningful way. To do this we chose the method developed by Ederer \& Mantel (1974) and recommended by Gardner \& Altman (1989b). The method gives the confidence interval for the ratio between two standardised ratios. A 95\% CI was chosen for this procedure also.

\section{The SMRs investigated}

First, the gender-specific all-causes SMRs were calculated. Next, the gender-specific SMRs for natural (malignant neoplasms, circulatory disorders and other somatic disorders) and unnatural (suicide, homicide, drug overdose death, accident and other violent) causes of death were investigated. The gender-specific all-causes SMRs were calculated for the main categories of DSM-IV mental disorders at index hospitalisation. The total patient sample was then dichotomised into two cohorts on the basis of year of birth. A total of 532 patients were born during 1945-1955, whereas the rest $(563$ patients) were born during 1956-1968. Gender-specific all-causes SMRs were investigated for these two cohorts. Next, the observation period for each patient was divided into three age-spans: from first hospitalisation up to the age of 25 years; between the ages of 25 and 34 years; and 35 years and above. Gender-specific all-cause SMRs were then calculated for these ages.

\section{RESULTS}

\section{Cause-specific SMRs}

The all-causes SMRs were significantly increased in both genders, with an all-causes death risk seven times that expected in both males and females. On dichotomising causes of death into natural and unnatural causes, the SMRs remained significantly raised. In males, the mortality risk from unnatural causes was 8.5 times that expected and from natural causes it was four times that expected. In females, the mortality risk from unnatural causes was almost 16 times that expected and from natural causes it was 2.5 times that expected. Looking into specific causes of death, the mortality risk was significantly raised for almost all the causes investigated. In males, the mortality risk from drug overdosing was 54 times that expected and for homicide it was 13 times that expected. The only SMR not found to be significantly raised in males was in neoplasms. In females, the mortality risk from drug overdosing was 83 times that expected and from suicide it was 19 times that expected. In females, the mortality risk was not significantly raised in neoplasms, circulatory disease or homicide. The SMRs with $95 \%$ CIs for all the causes of death investigated are given in Table 1.

Looking at the relative contribution of unnatural and natural causes of death to the overall mortality, we found that unnatural causes accounted for $75.2 \%$ of all deaths in males and for $76.2 \%$ of all deaths in females. Taking into account the expected mortality rates, we found that unnatural deaths accounted for $77.6 \%$ of all excess deaths in males and $83.2 \%$ of all excess deaths in females.

\section{Mental disorder-specific SMRs}

In males, all-causes SMRs were significantly raised in all psychiatric disorders, ranging from 2750 in PSUD to 390 in psychotic disorders. In females, SMRs were significantly raised in all disorders except organic disorders, affective disorders and anxiety

Table I All-causes standardised mortality ratios (SMRs) and cause-specific SMRs in male and female adolescent psychiatric in-patients

\begin{tabular}{|c|c|c|c|c|c|c|c|c|}
\hline \multirow[t]{2}{*}{ Cause of death } & \multicolumn{4}{|c|}{ Males $(n=588)$} & \multicolumn{4}{|c|}{ Females $(n=507)$} \\
\hline & $\begin{array}{l}\text { Observed } \\
\text { deaths }\end{array}$ & $\begin{array}{l}\text { Expected } \\
\text { deaths }\end{array}$ & SMR & $95 \% \mathrm{Cl}$ & $\begin{array}{l}\text { Observed } \\
\text { deaths }\end{array}$ & $\begin{array}{l}\text { Expected } \\
\text { deaths }\end{array}$ & SMR & $95 \% \mathrm{Cl}$ \\
\hline All causes & 105 & 15.25 & 6891 & $563-834$ & 42 & 5.98 & $702^{\prime}$ & $506-949$ \\
\hline Unnatural & 79 & 9.31 & 8491 & $672-1060$ & 32 & 2.02 & $1580^{\prime}$ & $1080-2240$ \\
\hline Drug overdose & 33 & 0.61 & $5410^{1}$ & $3290-8340$ & 10 & 0.12 & $8330^{\prime}$ & $3100-17800$ \\
\hline Suicide & 18 & 2.65 & 6791 & $337-1210$ & 15 & 0.79 & $1900^{\prime}$ & $1060-3130$ \\
\hline Homicide & 3 & 0.23 & $1300^{\prime}$ & $147-4770$ & I & 0.12 & 833 & $4-6190$ \\
\hline $\begin{array}{l}\text { Accidents and other } \\
\text { violent causes }\end{array}$ & 25 & 5.83 & 4291 & $278-633$ & 6 & 0.99 & $606^{1}$ & $222-1320$ \\
\hline Natural & 26 & 5.94 & $438^{\prime}$ & $286-641$ & 10 & 3.96 & $253^{\prime}$ & $|2|-464$ \\
\hline Neoplasm & 5 & 1.80 & 278 & $90-648$ & 2 & 2.02 & 99 & $5-459$ \\
\hline Circulatory & 8 & 1.29 & $620^{\prime}$ & $199-1440$ & I & 0.51 & 196 & $I-I 460$ \\
\hline Other natural causes & 13 & 2.85 & $456^{1}$ & $243-780$ & 7 & $\mathrm{I} .43$ & $490^{1}$ & $197-1010$ \\
\hline
\end{tabular}

I. The SMR is significantly increased. 
disorders. In females, the mortality risk was highest in PSUD (28 times that expected), followed by a mortality risk of 11 times that expected in psychotic disorders. The SMRs, including the $95 \%$ CIs, for all the mental disorders investigated are given in Table 2 .

\section{Cohort-specific SMRs}

The cohort-specific SMRs were significantly elevated for both genders in both cohorts investigated. In males, the mortality risk for the older cohort was five times that expected but in the younger cohort it was 10 times that expected. In females, the mortality risk was six times that expected in the older cohort and nine times that expected in the younger cohort. The gender-specific SMRs found for the two cohorts, including the $95 \%$ CIs, are given in Table 3.

Investigating the ratio between these SMRs (Ederer \& Mantel, 1974), we found that in males the $\mathrm{SMR}_{>1956}: \mathrm{SMR}_{<1956}$ ratio was 2.04 (95\% CI=1.37-3.15), indicating that the increase was significant. In females, the corresponding ratio was 1.47 (95\% CI $=0.29-1.64)$, indicating that the increase was non-significant.

\section{Age-specific SMRs}

The SMR was significantly raised in both genders for all three age-spans investigated. The mortality risk was highest in the 25 34-year age-span in both genders, with a mortality risk nine times that expected in males and 10.5 times that expected in females. Gender-specific SMRs, including

Table 2 Mental disorder-specific standardised mortality ratios (SMRs) in 588 male and 507 female adolescent psychiatric in-patients

\begin{tabular}{|c|c|c|c|c|c|c|c|c|c|c|}
\hline \multirow[t]{2}{*}{ Psychiatric diagnosis' } & \multicolumn{5}{|c|}{ Males } & \multicolumn{5}{|c|}{ Females } \\
\hline & $n$ & $\begin{array}{c}\text { Observed } \\
\text { deaths }\end{array}$ & $\begin{array}{l}\text { Expected } \\
\text { deaths }\end{array}$ & SMR & $95 \% \mathrm{Cl}$ & $n$ & $\begin{array}{c}\text { Observed } \\
\text { deaths }\end{array}$ & $\begin{array}{l}\text { Expected } \\
\text { deaths }\end{array}$ & SMR & $95 \% \mathrm{Cl}$ \\
\hline PSUD & 23 & II & 0.40 & $2750^{2}$ & $1370-4920$ & 43 & 9 & 0.32 & $2810^{2}$ & $1290-5340$ \\
\hline DBD+PSUD & 102 & 27 & 2.33 & $1160^{2}$ & $764-1690$ & 79 & 8 & 0.88 & $909^{2}$ & $392-1790$ \\
\hline DBD -PSUD & 233 & 36 & 6.23 & $578^{2}$ & $405-800$ & 82 & 5 & 1.23 & $407^{2}$ & $132-949$ \\
\hline Psychotic disorder & 54 & 6 & $\mathrm{I} .54$ & $390^{2}$ & $143-848$ & 44 & 6 & 0.53 & $1130^{2}$ & $415-2460$ \\
\hline Affective disorder & 31 & 5 & 0.87 & $575^{2}$ & $187-1340$ & 45 & 2 & 0.54 & 370 & $45-1340$ \\
\hline Anxiety disorder & 33 & 4 & 0.92 & $435^{2}$ & $118-1110$ & 32 & I & 0.41 & 244 & $6-1360$ \\
\hline Personality disorder & 47 & 7 & 1.13 & $619^{2}$ & $249-1280$ & 105 & 8 & 1.20 & $667^{2}$ & $288-1310$ \\
\hline Organic disorder & 32 & 5 & 0.92 & $543^{2}$ & $176-1270$ & 24 & I & 0.31 & 323 & $8-1800$ \\
\hline Other mental disorder & 33 & 5 & 0.92 & $543^{2}$ & $176-1270$ & 53 & 3 & 0.51 & $588^{2}$ & $121-1720$ \\
\hline
\end{tabular}

I. PSUD, psychoactive substance use disorder; DBD, disruptive behaviour disorder

2. The SMR is significantly increased.

Table 3 Cohort-specific standardised mortality ratios (SMRs) in 588 male and 507 female adolescent psychiatric in-patients

\begin{tabular}{|c|c|c|c|c|c|c|c|c|c|c|}
\hline \multirow[t]{2}{*}{ Cohort } & \multicolumn{5}{|c|}{ Males } & \multicolumn{5}{|c|}{ Females } \\
\hline & $n$ & $\begin{array}{c}\text { Observed } \\
\text { deaths }\end{array}$ & $\begin{array}{c}\text { Expected } \\
\text { deaths }\end{array}$ & SMR' & $95 \% \mathrm{Cl}$ & $n$ & $\begin{array}{c}\text { Observed } \\
\text { deaths }\end{array}$ & $\begin{array}{c}\text { Expected } \\
\text { deaths }\end{array}$ & SMR' & $95 \% \mathrm{Cl}$ \\
\hline Born 1945-1955 & 274 & 46 & 9.31 & 494 & $362-659$ & 258 & 26 & 4.12 & 631 & $412-926$ \\
\hline Born 1956-1968 & 314 & 60 & 5.96 & 1006 & $768-1296$ & 249 & 17 & 1.83 & 929 & $540-1490$ \\
\hline
\end{tabular}

I. The SMR values are significantly increased.

Table 4 Age-specific standardised mortality ratios (SMRs) in male and female adolescent psychiatric in-patients

\begin{tabular}{|c|c|c|c|c|c|c|c|c|c|c|}
\hline \multirow[t]{2}{*}{ Age (years) } & \multicolumn{5}{|c|}{ Males } & \multicolumn{5}{|c|}{ Females } \\
\hline & $n$ & $\begin{array}{c}\text { Observed } \\
\text { deaths }\end{array}$ & $\begin{array}{l}\text { Expected } \\
\text { deaths }\end{array}$ & $S M R^{\prime}$ & $95 \% \mathrm{Cl}$ & $n$ & $\begin{array}{c}\text { Observed } \\
\text { deaths }\end{array}$ & $\begin{array}{l}\text { Expected } \\
\text { deaths }\end{array}$ & $S M R^{\prime}$ & $95 \% \mathrm{Cl}$ \\
\hline$<25$ & 588 & 29 & 5.88 & 493 & $330-708$ & 507 & 12 & 1.58 & 759 & $392-1330$ \\
\hline $25-34$ & 559 & 48 & 5.20 & 923 & $681-1220$ & 495 & 20 & 1.91 & 1050 & $640-1620$ \\
\hline$\geqslant 35$ & 511 & 29 & 4.19 & 692 & 464-994 & 475 & II & 2.45 & 449 & $224-803$ \\
\hline
\end{tabular}

I. The SMR values are significantly increased. 
the $95 \%$ CIs, for the three age-spans investigated are given in Table 4 .

\section{DISCUSSION}

Ours is a nationwide patient sample large enough to enable us to perform genderspecific mortality analyses regarding cause of death, psychiatric diagnosis, cohort and age. Owing to the nationwide nature of the sample, the total Norwegian population was the preferred reference population. The use of such a large reference population (about 4 million) offered a high stability in the mortality rates used to calculate expected deaths. The proportion of patients traced at follow-up was high, compared to the long follow-up period. It is unlikely that those who were not investigated represent a selection-biased group.

Most other studies rely on the old diagnoses given at discharge from hospital (Goldacre \& Hawton, 1985; Kuperman et al, 1988; Rydelius, 1988; de Chateau, 1990; Larsen et al, 1990; Östman, 1991). This study has rediagnosed all patients using DSM-IV, a criterion-based diagnostic system currently in widespread international use. An interrater study with satisfactory results was conducted to ensure the quality of the diagnostic procedure.

The population investigated does evidently consist of the most severe cases in the country over the admission period, thus representing a population of 'worst cases' adolescent psychiatric in-patients. One important question is the degree to which the results can be generalised to adolescent psychiatric in-patients of today. This is a problem inherent to all long-term follow-up studies. Although the overall composition of adolescent psychiatric in-patients most likely has changed considerably over these years, it might be that a sample of the most disturbed patients has not changed to the same extent. The most disturbed adolescent psychiatric patients of today have a high frequency of comorbidity (Lewinsohn et al, 1995), and the picture is often complicated by drug misuse (Bukstein et al, 1989). These characteristics also apply to our study population.

\section{Cause-specific SMRs}

In their meta-analysis, Harris \& Barraclough (1998) found an all-causes SMR of 448 in male and 367 in female child and adolescent psychiatric patients. The higher rates in our sample might be due partly to the high proportion of PSUD and other comorbidity. It might also be that a population of mixed child and adolescent psychiatric patients carries a lower mortality risk than a pure adolescent psychiatric population. Our study population consisted of in-patients only who may have a higher mortality risk than a mixture of in- and out-patients. In the meta-analysis, adult psychiatric in-patients had generally lower SMRs than ours. Our results were more similar to the SMR of 599 found in a probationary school clientele (Rydelius, 1988).

Our finding of unnatural causes accounting for $75.2 \%$ of all deaths in males and for $76.2 \%$ of all deaths in females is in accordance with Harris \& Barraclough's meta-analysis (1998), which found that child and adolescent psychiatric patients had a high percentage of unnatural deaths $(>70 \%)$. Also, regarding excess mortality, our results are in line with the meta-analysis, which demonstrated an excess from unnatural causes of about $80 \%$. The findings are similar to those of de Chateau (1990), who found that $82 \%$ of the deaths occurring in his sample from a child guidance clinic were caused by suicide, homicide, accidents or PSUD.

The suicide risk in males was close to seven times the suicide risk in the general population, and it was even more markedly raised (19 times) in females. These suicide rates are far above the suicide risk found in child and adolescent psychiatric patients in the meta-analysis of Harris \& Barraclough (1998) and are comparable only to the SMRs of 960 in male and 1244 in female adult psychiatric in-patients in the same review article. Our finding of a higher suicide SMR in females than in males is concordant with studies of adult patients with various mental disorders (Harris \& Barraclough, 1998).

The increased risk of natural deaths is comparable to that found in most categories of psychiatric patients investigated (Harris \& Barraclough, 1998), and might be due to poor social circumstances, a high frequency of heavy smokers and somatic complications due to alcohol and drug misuse, that is, cirrhosis of the liver and AIDS. It has been suggested also that the increase might be partly because patients with serious, often undetected, physical disorders are selectively referred to psychiatric clinics (Martin et al, 1985).

\section{Mental disorder-specific SMRs}

As there has not, to our knowledge, been any large study of mortality in adolescent psychiatric in-patients relative to specific mental disorders, we found a comparison of our results with those of Harris \& Barraclough's (1998) comprehensive metaanalysis of mortality in various mental disorders in general to be most meaningful, although they pertain to adult patients. In the vast majority of disorders investigated by us, the mortality risk was higher in our adolescent population than in the adult populations in the meta-analysis.

We have reported elsewhere (Kjelsberg \& Dahl, 1999) that $72 \%$ of our patients with DBD, most of them males, had a criminal record at follow-up. We therefore compared our results regarding this particular patient group with those of Reiter (1974), who investigated a group of mentally ill males in a forensic psychiatric unit in Sweden. He found an SMR of 340, which is still well below the SMRs of 1160 and 578 found in our DBD males, relative to concurrent PSUD or not.

The mortality risk in our patients with psychotic disorders was markedly higher than in any of the psychotic subgroups of Harris \& Barraclough's (1998) metaanalysis. This might imply that the mortality risk in psychotic disorders is highest in patients with adolescent debut. We found a markedly higher mortality risk in females than in males with psychotic disorder, a gender difference not found in adults in the meta-analysis. Females with an adolescent debut of psychosis might be a high-risk group for premature death.

Comparing our results in the PSUD group with those of adult mixed-drug abusers in the meta-analysis, our all-causes SMRs of 2750 in males and 2810 in females were high compared with their corresponding ratios of 495 and 444. This marked difference is most likely due to our selected material of severely disordered and often comorbid in-patient drug addicts.

\section{Cohort-specific SMRs}

The increase in SMR from the 1945-1955 cohort to the 1956-1968 cohort can be explained by a marked increase in overdose deaths and suicides from the older to the younger cohort, an increase that is paralleled in the general population of Norway. Only the increase in the male population was significant, though. It is important to investigate further whether this cohort effect of increased mortality in adolescent psychiatric in-patients continues in the future. 


\section{Age-specific SMRs}

The pattern of an initial increase in SMR in adolescents throughout their mid-20s and then a subsequent decrease in SMR has been found in other populations too. Zilber (Zilber et al, 1989) found that the SMR increased from 417 in 10-19-year-olds to 798 in $20-39$-year-olds, after which the SMR steadily decreased down to 163 in those 70 years or older. Other studies have found similar trends, although less marked (Black et al, 1985; Martin et al, 1985; Casadebaig \& Quemada, 1989; Amaddeo et al, 1995; Hansen et al, 1997). It is important to realise, however, that all these results pertain to psychiatric patients in general, and not to adolescent psychiatric in-patients growing older, as in our sample.

\section{ACKNOWLEDGEMENTS}

This study has been supported by a grant from the Foundation for Health and Rehabilitation through the Norwegian Council for Mental Health. Professor Alv A. Dahl has given valuable comments and advice. The National Death Cause Registry provided the statistical material.

\section{REFERENCES}

Amaddeo, F., Bisoffi, G., Bonizzato, P., et al (1995) Mortality among patients with psychiatric illness. A tenyear case register study in an area with a communitybased system of care. British Journal of Psychiatry, 166, 783-788.

American Psychiatric Association (1994) Diagnostic and Statistical Manual of Mental Disorders (4th edn) (DSM-IV). Washington, DC: American Psychiatric Association.

Black, D. W., Warrack, G. \& Winokur, G. (1985) The lowa record-linkage study I. Suicides and accidental deaths among psychiatric patients. Archives of General Psychiatry, 42, 71-75.

Bukstein, O. G., Brent, D. A. \& Kaminer, Y. (1989) Comorbidity of substance abuse and other psychiatric disorders in adolescents. American Journal of Psychiatry, 146, $|13|-|| 4 \mid$.

Casadebaig, F. \& Quemada, N. (1989) Mortality in psychiatry inpatients. Acta Psychiatrica Scandinavica, $\mathbf{7 9}$ 257-264.

de Chateau, P. (1990) Mortality and aggressiveness in a 30 -year follow-up study in child guidance clinics in Stockholm. Acta Psychiatrica Scandinavica, 8I, 472-476.

Ederer, F. \& Mantel, N. (1974) Confidence limits on the ratio of two Poisson variables. American Journal of Epidemiology, 100, 165-167.

\section{CLINICAL IMPLICATIONS}

- Adolescent psychiatric in-patients are at high risk of premature death.

- The frequencies of both natural and unnatural causes of death are increased.

- The mortality is highest in the 25-34-year-old age group.

\section{LIMITATIONS}

- The results pertain to adolescent psychiatric in-patients only and are not representative of adolescent psychiatric patients in general.

- The comorbidity rates are higher than in adolescent psychiatric patients in general and might partly explain the high mortality rates.

- The diagnoses were given retrospectively.

ELLEN KJELSBERG, MD, Centre for Child and Adolescent Psychiatry, PO Box 26, Vinderen, N-0319 Oslo, Norway

(First received 24 May 1999, final revision 8 September 1999, accepted 10 September 1999)

Gardner, M. J. \& Altman, D. G. (1989a) Confidence Interval Analysis. Version I.I. London: British Medical Journal.

— $\boldsymbol{\&}$ _ (1989b) Statistics with Confidence. Belfast: British Medical Journal.

Goldacre, M. \& Hawton, K. (1985) Repetition of selfpoisoning and subsequent death in adolescents who take overdoses. British Journal of Psychiatry, 146, 395-398.

\section{Hansen, V., Arnesen, E. \& Jacobsen, B. K. (1997)}

Total mortality in people admitted to a psychiatric hospital. British Journal of Psychiatry, 170, 186-190.

\section{Harris, E. C. \& Barraclough, B. (1998) Excess} mortality of mental disorder. British Journal of Psychiatry I73, II-53.

Kjelsberg, E. \& Dahl, A. A. (1998) High delinquency, disability, and mortality - a register study of former adolescent psychiatric inpatients. Acta Psychiatrica Scandinavica, 98, 34-40.

_ \& _ (1999) A long-term follow-up study of adolescent psychiatric in-patients. Part II. Predictors of delinquency. Acta Psychiatrica Scandinavica, 99, 237-242.

Kuperman, S., Black, D. W. \& Burns, T. L. (1988) Excess mortality among formerly hospitalized child psychiatric patients. Archives of General Psychiatry, 45 277-282.

Larsen, F. W., Dahl, V. \& Hallum, E. (1990) A 30 -year follow-up study of a child psychiatric clientele. I.
Demographic description. Acta Psychiatrica Scandinavica, 8I, 39-45.

Lewinsohn, P. M., Rohde, P. \& Seeley, J. R. (1995) Adolescent psychopathology: III. The clinical consequences of comorbidity. Journal of the American Academy of Child and Adolescent Psychiatry, 34, 510-519.

Martin, R. L., Cloninger, C. R., Guze, S. B., et al (1985) Mortality in a follow-up of 500 psychiatric outpatients. II. Cause-specific mortality. Archives of General Hospital, 42, 58-66.

Östman, O. (1991) Child and adolescent psychiatric patients in adulthood. Acta Psychiatrica Scandinavica, 84 $40-45$

Reiter, K. (1974) Mortality and causes of death in men found to be mentally abnormal by forensic psychiatrists. Scandinavian Journal of Social Medicine, 2, 1-3.

Rydelius, P. A. (1988) The development of antisocial behaviour and sudden violent death. Acta Psychiatrica Scandinavica, 77, 398-403.

World Health Organization (1977) The Ninth Revision of the International Classification of Diseases and Related Disorders (9th revision) (ICD-9). Geneva: WHO.

Zilber, N., Schufman, N. \& Lerner, Y. (1989) Mortality among psychiatric patients - the groups at risk. Acta Psychiatrica Scandinavica, 79, 248-256. 